\title{
Ann Arbor Stage IIE
}

National Cancer Institute

\section{Source}

National Cancer Institute. Ann Arbor Stage IIE. NCI Thesaurus. Code C150548.

An Ann Arbor classification lymphoma stage term that refers to the involvement of a

single extranodal organ or site plus its regional lymph nodes with or without other lymph

nodes involvement on the same side of the diaphragm. 